\title{
The influence of depressive symptoms on executive functioning in binge eating disorder: A comparison of patients and non-obese healthy controls
}

\author{
Alexandra E. Dingemans ${ }^{\mathrm{a}, \mathrm{b}, *}$, Christine B. Vanhaelen ${ }^{\mathrm{a}}$, Jiska J. Aardoom ${ }^{\mathrm{c}}$, Eric F. van Furth ${ }^{\mathrm{a}, \mathrm{d}}$ \\ ${ }^{a}$ Rivierduinen Eating Disorders Ursula, Leiden, the Netherlands \\ ${ }^{\mathrm{b}}$ Institute of Psychology, Leiden University, Leiden, the Netherlands \\ ${ }^{\mathrm{c}}$ Department of Public Health and Primary Care, Leiden University Medical Center, Leiden, the Netherlands \\ ${ }^{\mathrm{d}}$ Department of Psychiatry, Leiden University Medical Center, Leiden, the Netherlands
}

A R T I C L E I N F O

\section{Keywords:}

Binge eating disorder

Executive functioning

Depressive symptoms

Neuropsychological tests

\begin{abstract}
A B S T R A C T
Executive functions are a set of cognitive processes that are necessary for the cognitive control of behavior. They play a role in mediating self-control, self-regulation and decision-making. It has been suggested that the inability to control eating behavior in binge eating disorder (BED) may indicate deficits in executive functioning. This may be worsened by depressive symptoms. The aim of the present study was to compare executive functioning of patients with BED and no-to-mild depressive symptoms $(n=25)$, patients with BED and moderate-to-severe depressive symptoms $(n=66)$, and healthy controls (Body Mass Index $<30)(n=56)$, matched on age, educational level and gender. The participants were assessed by means of neuropsychological tests and questionnaires. The neuropsychological tests did not show significant differences in executive functioning between the groups. However, eating disorder psychopathology and depressive symptoms are associated with self-reported difficulties in executive functioning in daily life. A self-report questionnaire which evaluates the functional, real-world impact of executive dysfunction expressed in everyday activities seems to be more useful in this population than neuropsychological tests. This study highlights the importance of taking depressive symptoms into account when studying executive functioning in patients with (binge) eating disorders.
\end{abstract}

\section{Introduction}

Binge eating disorder (BED) is characterized by recurrent episodes of binge eating (at least once a week) which are defined as eating an unusual amount of food within a limited period of time while experiencing loss of control without inappropriate compensatory behaviors (i.e., self-induced vomiting, misuse of laxatives, excessive exercising or fasting) (American Psychiatric Association, 2013). Binge eating may occur as the result of an inability to regulate intense emotions (Leehr et al., 2015). Individuals with BED appear to be less capable of coping with depressive feelings and are therefore more likely to engage in undesirable coping strategies, such as binge eating (Dingemans et al., 2017). Binge eating may serve as a means to escape from these negative thoughts and worries, and to alleviate emotional distress (Heatherton and Baumeister, 1991).

Executive functions are a set of cognitive processes that are necessary for the cognitive control of behavior. They play an important role in mediating self-control, self-regulation and decision-making. Executive functions are intrinsic to the ability to respond to novel situations in an adaptive manner and they form the basis of many cognitive, emotional and social skills (Lezak et al., 2011). It has been proposed that inefficiencies in executive functioning preexist and underlie the etiology of eating disorders development and relapse (Lena et al. 2004). Recent reviews and meta-analyses have reported inefficiencies in several executive functions in individual with eating disorders. However, for BED the results are mixed and the number of studies is limited (Kittel et al., 2015; Lavagnino et al., 2016; Van den Eynde et al., 2011; Voon, 2015; Wu et al., 2013a,b, 2014, 2016). When comparing individuals with BED to normal-weight, healthy controls, the majority of the studies and meta-analyses have found differences in response inhibition (Aloi et al., 2015; Davis et al., 2010; Kittel et al., 2017; Lavagnino et al., 2016; Mobbs et al., 2011; Mole et al., 2015) and decision making abilities (Danner et al., 2012; Davis et al., 2010; Manasse et al., 2015; Svaldi et al., 2010; Voon et al., 2014; Wu et al., 2013a,b), whereas the results for set-shifting abilities are somewhat mixed (Aloi et al., 2015; Kittel et al., 2017), and only one study (Aloi et al., 2015) has been conducted regarding central coherence, which demonstrated no differences between these groups. Since, age,

\footnotetext{
* Corresponding author at Rivierduinen Eating Disorder Ursula, P.O. Box 405, 2300 AK Leiden, the Netherlands.

E-mail address: a.dingemans@rivierduinen.nl (A.E. Dingemans).
} 
gender and educational level are correlated with neuropsychological test performances (Dohle et al., 2017; Strauss et al., 2006) it is important to match patient and control samples on these variables. The individuals with BED who are primarily included in research trials (Keel and Brown, 2010) are often much older, primarily female, and with a lower degree of education than the student samples that are frequently used as control groups. Differences between the groups appeared to disappear when educational level was entered into the analysis (Davis et al., 2010; Kittel et al., 2017). It may be hypothesized that the differences in executive functioning that have been found between BED and healthy controls are the result of differences in age, gender and educational level.

When comparing individuals with BED to obese controls, a recent meta-analysis (Wu et al., 2016) found no differences between these individuals in reward-related decision making abilities. Furthermore, the majority of the studies including meta-analyses did not find any differences between individuals with BED and obese controls regarding response inhibition (Galioto et al., 2012; Lavagnino et al., 2016; Manasse et al., 2015; Mobbs et al., 2011; Mole et al., 2015; Svaldi et al., 2014; Wu et al., 2013a,b) and set-shifting (Duchesne et al., 2010; Galioto et al., 2012; Kelly et al., 2013; Kittel et al., 2017; Manasse et al., 2015; Svaldi et al., 2010). Finally, with respect to working memory, two studies found no differences between obese or overweight individuals with and without BED (Galioto et al., 2012; Manasse et al., 2015), whereas one study did (Duchesne et al., 2010).

In the field of major depressive disorder, a greater number of, and larger, studies have been conducted to answer the question of whether there is an association between this disorder and impairments in executive functioning (Snyder, 2013). Executive functioning appears to be negatively affected by depression, as it has been shown to decrease initiation and problem solving, affect planning, impair verbal fluency, and impede flexibility (McClintock et al., 2010; Snyder et al., 2013). Moreover, it has been proposed that impairments in executive functioning may be transdiagnostic intermediate phenotypes or risk factors for emotional, behavioral, and psychotic disorders (Nolen-Hoeksema and Watkins, 2011). The majority of individuals with BED have at least one lifetime comorbid psychiatric disorder (67-79\%), with mood disorders amongst the most prevalent (Hudson et al., 2007; Javaras et al., 2008). It has also been suggested that the severity of depressive symptoms is positively associated with impairments in cognitive flexibility in eating disorders (Dingemans et al., 2015; Roberts et al., 2010; Snyder, 2013). Thus, it is important for research studies investigating executive functioning in individuals with eating disorders to also take into account depressive symptoms.

Therefore, the first aim of the present study is to compare executive functioning (i.e. response inhibitions, decision making, set-shifting, working memory and central coherence) of patients with BED and noto-mild depressive symptoms, patients with BED and moderate-to-severe depressive symptoms, and healthy controls matched on age, educational level and gender. Our first hypothesis is that the three groups will differ with respect to executive functioning. More specifically, we expect that the BED group with moderate-to-severe depressive symptoms has the weakest executive functioning abilities compared to the BED group with no-to-mild depressive symptoms and the normal weight healthy control group. No differences were expected between the BED group with no-to-mild depressive symptoms and the normal weight healthy controls. A second aim of the study is to investigate the associations between inefficiencies in executive functioning and severity of eating disorder symptoms. In the case of BED, it has been hypothesized that the inability to control eating may indicate inefficiencies in executive functioning (Galioto et al., 2012; Manasse et al., 2014). Therefore, it is hypothesized that individuals with BED with a higher BMI, more severe global eating disorder psychopathology, higher frequency of objective binge eating episodes, and more severe depressive symptoms, are more impaired in executive functioning than those with less severe symptoms.

\section{Method}

\subsection{Participants}

All consecutive patients with a primary diagnosis of BED according to DSM-5 criteria (American Psychiatric Association, 2013), who presented themselves for treatment at our center between October 2012 and February 2016, were asked to participate in the study. Diagnoses were made by a multidisciplinary team of experienced clinicians (i.e. psychologists and psychiatrists) specialized in eating disorders, using questions from two standardized semi-structured interviews: the Eating Disorder Examination (Fairburn and Cooper, 1993) and the Longitudinal Interval Follow-up Evaluation (Keller et al., 1987; Krämer, 1996).

The healthy control participants were recruited between April 2013 and December 2016 by means of advertisements on the website of our mental health institution, a local newspaper, supermarkets, and a day care center. This control group was matched with the patient group by gender, age and educational level. Individuals were included in the control group if they did not answer positive on one of the screening questions of the MINI (Sheehan et al., 1998), did not have a lifetime diagnosis for an eating disorder, had a Body Mass Index (BMI) between 18.5 and 30 , and fell within the healthy range with regard to scores on the Beck Depression Inventory-II (BDI-II) (Van der Does, 2002) and the Eating Disorder Examination Questionnaire (EDE-Q) (Fairburn, 1993).

\subsection{Procedure and design}

Eligible participants with BED were sent an information letter requesting their participation in the study. Subsequently, one of the researchers provided them with written and oral information in person. For the individuals with BED, the study assessments were conducted prior to the start of treatment as part of the Routine Outcome Monitoring. Potential control participants were screened by telephone by means of the MINI-patient-screen questionnaire (Sheehan et al., 1998). If they were eligible, an appointment was made for the assessment.

All participants signed an informed consent form prior to the start of the study. The total duration of the assessment was approximately one hour in which three questionnaires (Eating Disorder ExaminationQuestionnaire (EDE-Q; Fairburn, 1993), Beck Depression Inventory- II (BDI-II; Beck et al., 1988; Van der Does, 2002) and Behavior Rating Inventory of Executive Function- Adult version (BRIEF-A-SR) (Roth et al., 2004) and six neuropsychological tests (see 2.3 Measures) were completed. The researchers were trained to use the instruments and did not have a therapeutic relationship with any of the participants. The study was approved by the local ethics committee (METIGG).

\subsection{Measures}

\subsubsection{Demographical and clinical variables}

Participants' marital status, socioeconomic status (homemaker/retired, full-time job/student, part-time job, or disabled), educational level (low, medium, high), age, lowest and highest BMI ever, duration of illness, use of psychotropic medication (yes/no), presence of diabetes (yes/no), and gastric banding/gastric bypass surgery/gastrectomy (yes/ no) were recorded.

\subsubsection{Eating disorder psychopathology}

The EDE-Q (Fairburn, 1993) is a self-report questionnaire used for the assessment of eating disorder-specific psychopathology over the past 28 days. The EDE-Q consists of 36 items. Fourteen items assess the frequency of core ED behaviors, including frequency of objective binge eating episodes, and 22 items assess the core attitudinal features of ED pathology. These 22 items can be answered on a 7-point Likert scale ranging from 0 'not one day' to 6 'every day'. A global score can be 
calculated by summing and averaging the 22 items. A higher score reflects more psychopathology (range 0-6). Weight and height were also measured and BMI was calculated accordingly (weight/height ${ }^{2}$ ).

\subsubsection{Depressive symptoms}

The Dutch version of the BDI-II (Beck et al., 1988; Van der Does, 2002) measures the severity of depressive symptoms and contains 21 items, each with four self-evaluative statements rated according to severity (scored from 0 to 3 ). The total score is the sum of the 21 items (range 0-63). The following guidelines are suggested as BDI cut-off scores: 0-19 for no-to-mild depressive symptoms, and 20-63 for moderate-to-severe depressive symptoms. The internal consistency of the Dutch version of the BDI-II was high for a psychiatric outpatient group and a healthy control group. Test-retest reliability in these same groups was also high (Van der Does, 2002). Cronbach's alpha was 0.84 in the healthy control group and 0.91 in the BED group separately and 0.96 for the whole sample.

\subsubsection{Response inhibition}

The Stroop Test was used to measure response inhibition (Stroop, 1935). It consists of three trials. First, individuals are given a list of the following colors: red, green, blue and yellow, and they are asked to read the words aloud. Second, individuals are presented with small rectangles in these colors. They are then asked to name the colors of the rectangles. Third, individuals are given a list of names of the four colors, but written in a different color text than that which they actually represent, and they are asked to read the words aloud. The relative difference in time between trial 1 and 3 is used as a measure for response inhibition. A smaller difference reflects better response inhibition.

\subsubsection{Decision making}

A computerized adaptation (Mueller, 2009) of the Iowa Gambling Task (IGT) (Bechara et al., 1994) was used to measure decision making ability. Each participant was given a virtual amount of 2000 dollars of play money. Participants were presented with four virtual decks of cards (A-B-C-D) on a computer screen. By selecting one of the decks they either 1) gained, or 2) gained and lost, virtual money. The goal of the task was to make as much profit as possible. Decks A and B were disadvantageous in the long run because the total gains were lower than the total losses. Decks C and D were advantageous decks because although the gains were lower, the losses were also lower. Performance on the gambling task was measured by calculating a total score (the total number of advantageous choices (decks $C$ and D) minus the number of disadvantageous choices (decks A and B)), and by dividing the 100 card choices in five blocks of 20 trials to investigate the learning effect. Higher scores indicate better performance.

\subsubsection{Set-shifting}

The Trail Making -Test (TMT) (Reitan, 1956) consists of two parts in which an individual is instructed to connect a set of 25 dots as fast as possible while still maintaining accuracy. A computerized adaptation was used (Buro Tester, 2006b), in which the dots were presented on a computer screen. It required participants to complete a 25 -item numeric sequence (Trail A: $1-2-3$, etc.) and then a 25 -item numeric-alphabetical sequence (Trail B: 1-A-2-B-3-C, etc.). Set-shifting outcome score was defined as the difference in time (seconds) between part $\mathrm{B}$ minus part A, in order to control for baseline motor speed. A higher score reflected more set-shifting deficits.

The Wisconsin Card Sorting Task (WCST) (Heaton et al., 1993) instructed participants to match stimulus cards with one of four category cards that vary in geometric shapes, color, and number of items per card. A computerized adaptation was used (Buro Tester, 2006a). The participant was not informed about the sorting rule (i.e. shape, color or number) required for correct matching, but after each guess, the words 'right' or 'wrong' appeared on the screen. The participant therefore had to discover the sorting rule, which changed without warning during the course of the task after 10 consecutive correct matched cards. The number of perseverative errors was used as a measure of set-shifting ability.

\subsubsection{Working memory}

Working memory was assessed by the Digit Span, which is a subtest of the Wechsler Adult Intelligence Scale (WAIS-IV) (Wechsler, 2012). Individuals were given sets of digits to repeat forward, and then backward. It is a test of immediate auditory recall and freedom from distraction, which is assessed by the number of correct answers. After two incorrect answers of the same number of digits, the test was ended. A higher score on the digit span backwards indicated a better attention and working memory function.

\subsubsection{Central coherence}

The Rey Complex Figure Test (RCFT) (Osterrieth, 1944) assesses visual organization, visuospatial abilities and short-term visual memory. Participants were asked to copy a complex geometric figure. Five minutes later, without previous warning, participants were asked to reproduce this figure from memory. In accordance with Booth's scoring system (Booth, 2006), an order of construction score (i.e., the order in which the elements of the figure were drawn) and style score (i.e., continuity of drawing) were calculated. The Central Coherence Index (CCI) is the mean score of the order of construction and the style score. A lower CCI reflects weaker central coherence.

\subsubsection{Executive functioning in daily life}

In most studies, executive functioning is measured by means of neuropsychological tests, such as those listed above. However, since many of these tests are time intensive to administer, lack ecological validity (Rabin et al., 2006), and cannot be used a second time since these tests rely heavily on their novelty (Lezak et al., 2011), a selfreport questionnaire such as the Behavior Rating Inventory of Executive Function- Adult version (BRIEF-A-SR) may be useful (Roth et al., 2004). The questionnaire assesses a persons' own perception of their difficulties in executive functioning in daily life (Noens and Scholte, 2011). The inventory consists of 75 items which can be divided into nine subscales of self-reported behavior, as well as two summary index scales, and a scale for overall executive functioning. The four subscales 1) inhibit, 2) shift, 3) emotional control, and 4) self-monitor, form the behavioral regulation index, and the five subscales 1) initiate, 2) working memory, 3) plan/organize, 4) task monitor, and 5) organization of materials, comprise the metacognition index. The scores on all the subscales were converted into T-scores, with a mean of 50 and standard deviation of 10 based on age (Noens and Scholte, 2011). The questionnaire has demonstrated high internal consistency reliability and good ecological validity as it has been found to adequately assess the impact of executive functioning difficulties in common situations and everyday tasks (Rouel et al., 2016). Higher scores reflect more problems in executive functioning in daily life.

\subsection{Statistical analyses}

To investigate possible group differences regarding demographic and clinical variables between the two BED groups and the normal weight healthy control group ANOVA or chi-square tests were conducted. In order to investigate hypothesis 1 , a multivariate analysis of variance (MANOVA) was conducted with the scores on the neuropsychological tests and subscales of the BRIEF-A as the dependent variables and group (two BED groups and healthy control group) as the independent fixed factor. Neuropsychological test scores were categorized as deviant if they fell above or below one standard deviation of the healthy control mean (in the direction of poor task performance). One standard deviation was selected as a threshold due to the stated aim to investigate subtle neurocognitive inefficiencies rather than stark 
impairments in functioning (Roberts et al., 2016). Cases were then categorized as having poor executive functioning if they had an elevated score on at least half (i.e. three) of the administered tasks (Roberts et al., 2016). For all dependent variables, Levene's Test was conducted to assess the equality of variances for the three groups. When this assumption appeared to be violated, the alpha-level was adapted to the more conservative level of 0.01 (Tabachnick and Fidell, 2013). A priori we estimated that a total sample of 66 was needed for an estimated effect size of $f=0.40$ with a power of 0.80 and a $5 \%$ significance level to detect difference in means (ANOVA) between three groups. A total sample of 159 participants was needed for an estimated effect of $f=0.25$ (power 0.80 and alpha 0.05 ). Regarding hypothesis 2 , correlations (Pearson's $r$ for normally distributed variables and Spearman's $\rho$ for non-normally distributed variables) between BMI, eating disorder psychopathology severity scores (i.e. EDE-Q and frequency of objective binge episodes), depressive symptoms (BDI-II), and the neuropsychological test results and problems in executive functions in daily life (BRIEF-A behavioral regulation index and metacognition index) were examined within the BED sample. SPSS version 22 was used for all statistical analyses.

\section{Results}

\subsection{Participants}

The initial sample consisted of 91 patients with BED and 61 healthy controls. Four control participants had an EDE-Q global score that was higher than the cut-off of 2.17 (see for more details Dingemans et al., 2016) and were therefore excluded from the study. Furthermore, another control participant had a BDI-II total score of 22 and was also excluded from the study. Therefore, the final sample included 91 participants in the BED group and 56 in the normal weight healthy control group. Based on the proposed cut-off scores of the BDI-II, the BED sample was divided into two groups: one with no-to-mild depressive symptoms $(n=25)$ and another with moderate-to-severe depressive symptoms $(n=66)$. Due to a computer failure, the data of the WCST and TMT of one participant in the BED group, and the data of the IGT of one control participant, were lost.

The matching of the BED and healthy control participants was successful, as no differences were found in terms of age, gender and educational level (see Table 1). Also, in concordance with the inclusion and exclusion criteria, the control group had a significantly lower BMI, a lower level of eating disorder psychopathology, and a lower level of depressive symptoms than the two BED-groups. No significant differences were found between the BED group with no-to-mild and moderate-to-severe depressive symptoms with regard to BMI and frequency of objective binge episodes. Significant differences were found between the three groups with respect to the EDE-Q global score (see Table 1). Patients with moderate-to-severe depressive symptoms had the highest scores on the EDE-Q, the healthy controls had the lowest, and the patients with no-to-mild depressive symptoms presented intermediate scores. Finally, the moderate-to-severe depressed BED group was less likely to be employed than the other two groups.

\subsection{Group differences in executive functioning}

As can be seen in Table 1, no group differences were found for the neuropsychological tests measuring decision making, response inhibition, set-shifting, working memory and central coherence. Test scores of all individual neuropsychological tests were categorized into two categories based on whether they differed more or less than one standard deviation of the healthy control mean for the test. Test scores of most patients with BED fell within the healthy range (67-90\%). These percentages did not differ from the healthy controls. Only a small percentage presented inefficiencies in executive functioning on some of the tests without a clear pattern. The patients with moderate-to-severe depressive symptoms showed three or more inefficiencies slightly more often than the other two groups (see Table 1). With respect to executive functioning in daily life, as measured by a questionnaire (BRIEF-A-SR), the results completely confirmed our first hypothesis: the BED group with moderate-to-severe depressive symptoms showed the weakest executive functioning abilities in daily life, whereas the normal weight healthy control group showed the strongest abilities, and the BED group with no-to-mild depressive symptoms presented intermediate scores. Adding medication (yes/no) and psychiatric comorbidity (yes/no) as covariates in the model did not alter the results.

The results regarding our second hypothesis can be found in Table 2. First, no significant correlations were found between the outcomes of the neuropsychological tests of executive functioning and BMI, global eating disorder psychopathology, objective binge eating episodes, and depressive symptoms. However, a significant positive association was demonstrated between global eating disorder psychopathology and executive functioning in daily life in terms of both behavior and metacognition. Furthermore, more severe levels of depression were significantly correlated with weaker executive functioning abilities in daily life. No associations were found between the BRIEF-A and BMI and frequency of binge eating.

\section{Discussion}

The aim of the present study was to compare executive functioning (i.e. response inhibitions, decision making, set-shifting, working memory and central coherence) of patients with BED and no-to-mild depressive symptoms, patients with BED and moderate-to-severe depressive symptoms, and healthy controls matched on age, educational level and gender. Neuropsychological tests were used to measure executive functioning and a questionnaire assessed executive functioning in daily life.

The neuropsychological tests did not show significant differences in executive functioning between patients with BED with no-to-mild, and moderate-to-severe depression, and matched healthy controls. In line with our hypothesis and findings of Davis et al. (2010) and Kittel et al. (2017), no significant differences were found between patients with BED and controls as a result of matching on gender, age and level of education. Previous studies demonstrating deficits in response inhibition (Aloi et al., 2015; Mobbs et al., 2011; Mole et al., 2015) and decision making abilities (Danner et al., 2012; Manasse et al., 2015; Svaldi et al., 2010; Voon et al., 2014; Wu et al., 2013a,b) included control groups which consisted of younger and more highly educated individuals in comparison to the BED groups. Contrary to our expectations, no significant correlations were found between the outcomes of the neuropsychological tests of executive functioning and depressive symptoms.

In contrast with the non-significant differences between the subgroups regarding the neuropsychological tests, we found that patients with BED reported more deficits in executive functioning in daily life (as measured by the BRIEF-A-SR) compared to healthy controls. More specifically, the BED group with moderate-to-severe depressive symptoms reported the weakest executive functioning abilities in daily life, whereas the normal weight healthy control group reported the strongest abilities, and the BED group with no-to-mild depressive symptoms presented intermediate scores. Although the inability to control eating in BED may indicate inefficiencies in executive functioning (Galioto et al., 2012; Manasse et al., 2014), we failed to find an association between executive functioning in daily life and frequency of objective binge eating and BMI. This is in line with the majority studies that found no differences in executive functioning in obese individuals with and without BED (see introduction).

In line with Rouel et al. (2016), the BRIEF-A appeared more sensitive in detecting different levels of executive functioning between the healthy control group and the BED groups with and without depressive symptoms compared to traditional neuropsychological tests. One of the 
Table 1

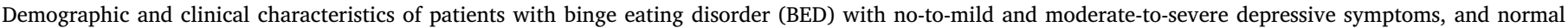
weight healthy controls.

\begin{tabular}{|c|c|c|c|c|c|}
\hline & $\begin{array}{l}\text { BED, no-to-mild } \\
\text { depressive symptoms } \\
(N=25)\end{array}$ & $\begin{array}{l}\text { BED, moderate-to- } \\
\text { severe depressive } \\
\text { symptoms }(N=66)\end{array}$ & $\begin{array}{l}\text { Normal weight healthy } \\
\text { controls }(N=56)\end{array}$ & $\begin{array}{l}\text { Test statistics and } \\
\text { significance }\end{array}$ & $\begin{array}{l}\text { Effect sizes (f): } \\
\text { overall }^{1}\end{array}$ \\
\hline Age (years), $M(S D)$ & $32.8(8.5)$ & $34.2(9.9)$ & $36.7(12.3)$ & $F(2,144)=1.4, p=0.25$ & \\
\hline Objective binge eating episodes (28 days), $M(S D)$ & $9.5(6.6)^{a}$ & $13.3(10.6)^{\mathrm{a}}$ & $0.4(1.8)^{\mathrm{b}}$ & $F(2,144)=42.7, p<0.001$ & \\
\hline EDE-Q global score, $M(S D)$ & $3.3(0.9)^{\mathrm{a}}$ & $4.1(0.8)^{\mathrm{b}}$ & $0.7(0.9)^{\mathrm{c}}$ & $F(2,144)=248.3, p<0.001$ & \\
\hline BMI $\left(\mathrm{kg} / \mathrm{m}^{2}\right), M(S D)$ & $38.5(7.4)^{\mathrm{a}}$ & $37.6(6.2)^{\mathrm{a}}$ & $23.5(2.8)^{\mathrm{b}}$ & $F(2,144)=119.1, p<0.001$ & \\
\hline BDI-II total score, $M(S D)$ & $12.3(4.4)^{\mathrm{a}}$ & $31.8(7.9)^{\mathrm{b}}$ & $2.9(4.1)^{\mathrm{c}}$ & $F(2,144)=348.1, p<0.001$ & \\
\hline Duration of illness (years), $M(S D)$ & $15.6(9.40$ & $16.1(11.9)$ & $\mathrm{n} / \mathrm{a}$ & $t(82)=-0.18, p=0.86$ & \\
\hline Diabetes (present: $\mathrm{n}, \%$ ) & $2(8)$ & $3(5)$ & $0(0)$ & $X^{2}(2)=3.1, p=0.22$ & \\
\hline Gastric by-pass/gastric band (present: $n, \%$ ) & $1(4)$ & $2(3)$ & $0(0)$ & $X^{2}(2)=1.47, p=0.48$ & \\
\hline Psychotropic mediation (present: $\mathrm{n}, \%$ ) & $6(24)$ & $29(45)$ & $1(2)$ & $X^{2}(2)=22.61 p<0.001$ & \\
\hline Comorbid psychiatric disorders (present: n, \%) & & & & $X^{2}(2)=34.6 p<0.001$ & \\
\hline None & $14(58)$ & $37(56)$ & $56(100)$ & & \\
\hline One & $9(38)$ & $22(33)$ & $0(0)$ & & \\
\hline Two or more & $1(4)$ & $7(11)$ & $0(0)$ & & \\
\hline Gender $(n, \%)$ & & & & $X^{2}(2)=2.25, p=0.25$ & \\
\hline Female & $22(88)$ & $63(95)$ & $49(87.5)$ & & \\
\hline Male & $3(12)$ & $3(5)$ & $7(12.5)$ & & \\
\hline Living situation, $n(\%)$ & & & & $X^{2}(6)=7.2, p=0.31$ & \\
\hline Living alone & $2(8)$ & $11(17)$ & $10(18)$ & & \\
\hline Living together/with children & $10(42)$ & $18(27)$ & $9(17)$ & & \\
\hline Living with parents & $10(42)$ & $31(47)$ & $32(59)$ & & \\
\hline Other & $2(8)$ & $6(9)$ & $3(6)$ & & \\
\hline Socio-economic status, $n(\%)$ & $3(12)$ & $8(12)$ & $5(9)$ & $X^{2}(8)=28.8, p<0.001$ & \\
\hline School/study & $18(72)^{\mathrm{a}}$ & $31(47)^{\mathrm{b}}$ & $49(88)^{\mathrm{a}}$ & & \\
\hline Employed & $2(8)$ & $9(14)$ & $2(4)$ & & \\
\hline Unemployed/homemaker & $2(8)$ & $16(24)$ & $0(0)$ & & \\
\hline Sick leave/disabled & $0(0)$ & $2(3)$ & $0(0)$ & & \\
\hline \multicolumn{6}{|l|}{ Other } \\
\hline Highest educational level, $n(\%)$ & & & & $X^{2}(4)=2.3, p=0.68$ & \\
\hline Lower secondary school & $1(4)$ & $8(12)$ & $4(7)$ & & \\
\hline Higher secondary school & $3(52)$ & $36(55)$ & $30(54)$ & & \\
\hline Bachelor/Master & $11(44)$ & $22(33)$ & $22(39)$ & & \\
\hline Response inhibition & $1.6(0.2)$ & $1.7(0.4)$ & $1.5(0.2)$ & $F(2,144)=3.8, p=0.03^{2}$ & $f=0.2$ \\
\hline \multicolumn{6}{|l|}{ Stroop test (trial $3 /$ trial 1 ), $M(S D$ ) } \\
\hline Decision making & $13.5(24.2)$ & $7.2(22.2)$ & $8.0(28.4)$ & $F(2,132)=0.6, p=0.55$ & $f=0.5$ \\
\hline \multicolumn{6}{|l|}{ Iowa Gambling Task total score, $M(S D)$} \\
\hline \multicolumn{6}{|l|}{ Set-shifting } \\
\hline Trail making test (trail C/trail A), $M(S D)$ & $1.4(0.4)$ & $1.5(0.4)$ & $1.4(0.4)$ & $F(2,143)=1.0, p=0.37$ & $f=0.1$ \\
\hline WCST number of perseverative errors, $M(S D)$ & $18.1(8.0)$ & $17.7(8.7)$ & $18.1(8.7)$ & $F(2,144)=0.03, p=0.97$ & $f=0.1$ \\
\hline WCST categories completed, $M(S D)$ & $6.8(2.4)$ & $6.0(3.0)$ & $6.1(2.8)$ & $F(2,144)=0.8, p=0.46$ & $f=0.2$ \\
\hline Working memory & $9.8(2.2)$ & $9.0(2.1)$ & $9.3(3.1)$ & $F(2,144)=0.9, p=0.40$ & $f=0.2$ \\
\hline Digit Span forward, number correct, $M(S D)$ & $7.2(2.0)$ & $6.8(2.2)$ & $6.1(2.9)$ & $F(2,144)=2.0, p=0.14$ & $f=0.3$ \\
\hline \multicolumn{6}{|l|}{ Digit Span backward, number correct, $M(S D)$} \\
\hline Central Coherence & $1.9(0.3)$ & $1.7(1.4)$ & $1.9(0.3)$ & $F(2,144)=1.3, p=0.29$ & $f=0.1$ \\
\hline \multicolumn{6}{|l|}{ Rey Complex Figure Test, CCI, $M(S D)$} \\
\hline Overall neuropsychological inefficiencies, $n$ (\%) & $25(100)^{\mathrm{a}}$ & $56(85)^{\mathrm{b}}$ & $52(95)^{\mathrm{a}}$ & $X^{2}(2)=6.4, p=0.04$ & \\
\hline Less than three neuropsychological tests & $0(0)$ & $10(15)$ & $3(5)$ & & \\
\hline \multicolumn{6}{|l|}{ Three or more neuropsychological tests } \\
\hline Executive functioning in daily life & $55.0(8.9)^{\mathrm{a}}$ & $67.5(8.8)^{\mathrm{b}}$ & $46.9(8.9)^{\mathrm{c}}$ & $F(2,144)=83.5, p<0.001$ & $f=3.2$ \\
\hline BRIEF-A Behavioral Index, $M(S D)$ & $59.5(10.8)^{\mathrm{a}}$ & $70.2(9.7)^{b}$ & $48.5(8.6)^{c}$ & $F(2,144)=79.3, p<0.001$ & $f=3.2$ \\
\hline
\end{tabular}

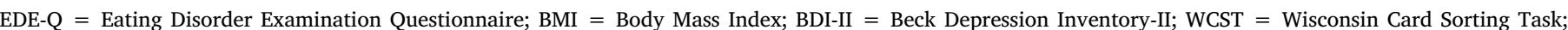
$\mathrm{CCI}=$ Central Coherence Index;

BRIEF-A = Behavior Rating Inventory of Executive Function-Adult version.

Note: Different superscript letters indicate significant group differences in Bonferonni post-hoc comparisons $(p<0.05)$.

1 Effect size (ANOVA) $f: 0.10$ (small); 0.25 (medium); 0.40 (large)

2 Levene's Test of Equality of Error Variances showed that there was no equality of variances for the three groups $(F(2,131)=5.07, p=0.008)$. This meant that a

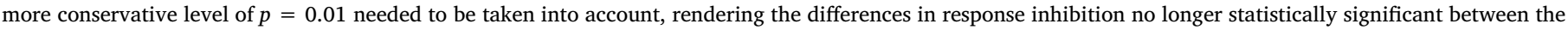
three groups.

problems with neuropsychological tests is that they attempt to separate executive functions into component parts (Burgess et al., 1998), whereas in real life people integrate these functions. Furthermore, hardly any neuropsychological test shows consistent impairments within disorders and across studies (Gioia and Isquith, 2004). Another critique of the traditional neuropsychological tests is that they measure executive functioning over a short time frame and do not capture all the integrated, multidimensional functions that are often demanded in realworld situations (Gioia and Isquith, 2004; Goldberg and Podell, 2000).
Furthermore, test environments are standardized conditions which are structured by the assessor (Blijd-Hoogewys et al., 2014) and are therefore not representative of the more complex functioning in daily life. Instead, these neuropsychological tests measure optimum performance with respect to executive functioning (Gioia and Isquith, 2004). Similar findings have also been found in samples with other psychiatric disorders (Hagen et al., 2016; McAuley et al., 2010). However, it may also be speculated that the BRIEF-A measures some underlying general psychopathology given the moderate correlation with depressive 
Table 2

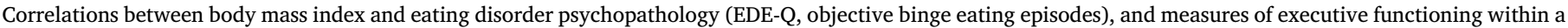
sample of individuals with BED $(N=91)$.

\begin{tabular}{|c|c|c|c|c|}
\hline & $\begin{array}{l}\text { Body Mass Index } \\
\text { Pearson } r\end{array}$ & $\begin{array}{l}\text { Eating disorder psychopathology } \\
\text { (EDE-Q) } \\
\text { Spearman } \rho\end{array}$ & $\begin{array}{l}\text { Objective binge eating episodes } \\
\text { (past } 28 \text { days) } \\
\text { Spearman } \rho\end{array}$ & $\begin{array}{l}\text { Depressive symptoms (BDI- } \\
\text { II) } \\
\text { Pearson } r\end{array}$ \\
\hline Response inhibition: Stroop task (trial 3-trial 1) & -0.05 & 0.19 & 0.12 & 0.12 \\
\hline Decision making: Iowa Gambling task (total score) & 0.05 & 0.10 & 0.02 & 0.004 \\
\hline \multicolumn{5}{|l|}{ Set-shifting } \\
\hline Trail Making Test (trail c-trail a) & 0.03 & 0.15 & -0.005 & 0.14 \\
\hline WCST (number of perseverative errors) & -0.09 & 0.14 & -0.14 & -0.07 \\
\hline \multicolumn{5}{|l|}{ Working memory: } \\
\hline Digit span forward (numbers correct) & -0.04 & -0.06 & 0.15 & -0.19 \\
\hline Digit span backward (numbers correct) & -0.04 & -0.01 & -0.03 & -0.13 \\
\hline Central coherence: Rey Complex Figure Task (CCI) & -0.15 & 0.005 & -0.13 & -0.004 \\
\hline \multicolumn{5}{|l|}{ Executive functioning in daily life } \\
\hline BRIEF-A Behavioral Index, $M(S D)$ & -0.11 & $0.32^{* *}$ & -0.07 & $0.58^{* *}$ \\
\hline BRIEF-A Metacognition Index, $M(S D)$ & -0.13 & $0.30^{* * *}$ & 0.13 & $0.51^{* * *}$ \\
\hline $\begin{array}{l}\text { Overall neuropsychological inefficiencies } \\
\text { Inefficiencies on }<3 \text { tests versus } \geq=3 \text { tests }\end{array}$ & 0.25 & 0.03 & 0.01 & $0.22^{*}$ \\
\hline
\end{tabular}

EDE-Q = Eating Disorder Examination Questionnaire; BED = Binge Eating Disorder; WCST = Wisconsin Card Sorting Task; CCI = Central Coherence Index; BRIEF-A = Behavior Rating Inventory of Executive Function-Adult version; BDI-II = Beck Depression Inventory-II.

${ }^{*} p<0.05$.

*** $p<0.01$.

symptoms (measured by the BDI-II) and low correlation with eating disorder psychopathology (measured by the EDE-Q) (see Table 2).

Both eating disorder psychopathology and depressive symptoms seem to be linked to impairments in executive functioning abilities in daily life. Other studies also found that depression severity seems to be associated with more cognitive impairment in eating disorders (Dingemans et al., 2015; Roberts et al., 2010) as well as in depressive disorders (McClintock et al., 2010). Rouel et al. (2016) also found a significant correlation between the BRIEF-A scales and depressive symptoms: i.e. more self-reported difficulties in executive functioning were related to more severe depressive symptoms.

The strengths of the present study lie in the fact that we recruited a large and representative sample of both patients with BED as well as healthy controls. In addition, patients with BED and healthy controls were carefully matched on age, educational level and gender. Furthermore, all consecutive patients were asked to participate in this study at the beginning of treatment, with only a few declining to participate. In other words, this sample is representative for a specialized eating disorders treatment center. Also, in this study, neuropsychological tests, as well as a self-report questionnaire, were used to measure executive functioning.

However, the results of this study must be considered in conjunction with a number of limitations. The first limitation is that IQ was not measured by means of for example the WAIS (Wechsler, 2012). However, the cases and controls in the current study were matched on educational level, which is highly associated with IQ. Since the WAIS is a very lengthy assessment, a short measure of IQ, for example the National Adult Reading Test (Nelson, 1991) could be administered in future. Men were under-represented in this study, since they are underrepresented in BED-health care in general (Dingemans et al., 2002). Future studies should pay extra attention to including men. Another limitation pertains to the generalizability of our study findings, given that our participants with BED were all individuals seeking treatment for their eating disorder. Individuals with BED are often reluctant to seek treatment for their binge eating and present themselves many years after the onset of binge eating, and therefore, patients who do seek help are often much older. Those who do not seek help are generally much younger and less likely to be obese (Dingemans and van Furth, 2012). Also, it may be important to use the full BRIEF-A instrument which includes an informant questionnaire (Rabin et al., 2006).

In conclusion, in our study we found no differences in executive functioning between patients with BED and healthy controls, when measured by means of neuropsychological tests. However, a different result was found when using a questionnaire (i.e. BRIEF-A-SR) assessing executive functioning in daily life. Patients with BED reported having more deficits in executive functioning in daily life compared to healthy controls. Moreover, patients with BED with more severe depressive symptoms reported more deficits in daily life than those with less severe depressive symptoms. Hence, a self-report questionnaire which evaluates the functional, real-world impact of executive dysfunction expressed in everyday activities seems to be more useful in this population than neuropsychological tests. It is important to compare patients with BED with a matched representative control group in order to obtain valid results. Matching on gender, age and level of education is important in order to eliminate potential confounders (Kittel et al., 2017; Davis et al., 2010). Furthermore, inefficiencies in executive functioning in patients with BED may be too subtle to be captured by traditional neuropsychological tests which are designed to measure more severe cognitive deficits. The next step with this line of research would be to replicate these findings and to compare patients with BED to those with a depressive disorder. This study highlights the importance of taking depressive symptoms into account when studying executive functioning in patients with (binge) eating disorders.

\section{Conflict of interest}

The authors declare no conflict of interest.

\section{Contribution}

All authors have seen and approved the manuscript being submitted. They warrant that the article is the authors' original work, has not received prior publication and is not under consideration for publication elsewhere.

\section{Acknowledgments}

The authors would like to thank Annemieke Haklander, Corina de Vos and Marlotte Staps for their help in the recruitment and testing of the participants for the study. 


\section{Supplementary materials}

Supplementary material associated with this article can be found, in the online version, at doi:10.1016/j.psychres.2019.02.033.

\section{References}

Aloi, M., Rania, M., Caroleo, M., Bruni, A., Palmieri, A., Cauteruccio, M.A., et al., 2015. Decision making, central coherence and set-shifting: a comparison between binge eating disorder, Anorexia Nervosa and healthy controls. BMC Psychiatry 15, 6. https://doi.org/10.1186/s12888-015-0395-z.

American Psychiatric Association, 2013. Diagnostic and Statistical Manual of Mental Disorders, Fifth Edition (DSM-5), Fifth ed. American Psychiatric Publishing, Arlington, VA.

Bechara, A., Damasio, A.R., Damasio, H., Anderson, S.W., 1994. Insensitivity to future consequences following damage to human prefrontal cortex. Cognition 50 (1-3), 7-15.

Beck, A.T., Steer, R.A., Garbin, M.G.,. Psychometric properties of the Beck Depression Inventory - 25 years of evaluation. Clin. Psychol. Rev. 8(1), 77-100. doi:10.1016/ 0272-7358(88)90050-5.

Blijd-Hoogewys, E.M.A., Bezemer, M.L., van Geert, P.L.C., 2014. Executive functioning in children with ASD: an analysis of the BRIEF. J. Autism Dev. Disord. 44 (12), 3089-3100. https://doi.org/10.1007/s10803-014-2176-9.

Booth, R., 2006. Local-global Processing and Cognitive Style in Autism Spectrum Disorders and Typical Development. King's College London, London.

Burgess, P.W., Alderman, N., Evans, J., Emslie, H., 1998. The ecological validity of tests of executive function. J. Int. Neuropsychol. Soc. 4, 547-558.

Buro Tester., 2006. Card Sorting Test (Version www.burotester.nl). Retrieved from. www.burotester.nl.

Buro Tester, 2006. Trailmaking Test (Version http://www.burotester.nl/). Retrieved from. www.burotester.nl.

Danner, U.N., Ouwehand, C., van Haastert, N.L., Hornsveld, H., de Ridder, D.T.D., 2012. Decision-making Impairments in women with binge eating disorder in comparison with obese and normal weight women. Eur. Eat. Disord. Rev. 20 (1), 56-62. https:// doi.org/10.1002/erv.1098.

Davis, C., Patte, K., Curtis, C., Reid, C., 2010. Immediate pleasures and future consequences. A neuropsychological study of binge eating and obesity. Appetite 54 (1), 208-213. https://doi.org/10.1016/j.appet.2009.11.002.

Dingemans, A.E., Bruna, M.J., van Furth, E.F., 2002. Binge eating disorder: a review. Int. J. Obes. 29 (3), 299-307. https://doi.org/10.1038/sj.ijo.0801949.

Dingemans, A.E., Danner, U.N., Parks, M., 2017. Emotion regulation in binge eating disorder: a review. Nutrients 9 (11), 1274. https://doi.org/10.3390/nu9111274.

Dingemans, A.E., van Furth, E.F., 2012. Binge eating disorder psychopathology in normal weight and obese individuals. Int. J. Eat. Disord. 45 (1), 135-138. https://doi.org/10. 1002/eat.20905.

Dingemans, A.E., van Son, G.E., Aardoom, J.J., Bruidegom, K., Slof, -, Op 't Landt, M.C.T., van Furth, E.F., 2016. Predictors of psychological outcome in patients with eating disorders: a routine outcome monitoring study. Int. J. Eat. Disord. 49 (9), 863-873. https://doi.org/10.1002/eat.22560.

Dingemans, A.E., Visser, H., Paul, L., van Furth, E.F., 2015. Set-shifting abilities, mood and loss of control over eating in binge eating disorder: an experimental study. Psychiatry Res. 230 (2), 242-248. https://doi.org/10.1016/j.psychres.2015.09.001.

Dohle, S., Diel, K., Hofmann, W., 2017. Executive functions and the self-regulation of eating behavior: a review. Appetite 124, 4-9. https://doi.org/10.1016/j.appet.2017. 05.041 .

Duchesne, M., Mattos, P., Appolinario, J.C., Regina de Freitas, S., Coutinho, G., Santos, C., Coutinho, W., 2010. Assessment of executive functions in obese individuals with binge eating disorder. Rev. Bras. Psiquiatr. 32 (4), 381-388. https://doi.org/10. 1590/S1516-44462010000400011.

Fairburn, C.G., 1993. Overcoming Binge Eating. The Guilford Press, New York.

Fairburn, C.G., Cooper, Z., 1993. The eating disorder examination. In: Fairburn, C.G., Wilson, G.T. (Eds.), Binge eating: Nature, Assessment and Treatment. Guilford Press, New York, pp. 317-360.

Galioto, R., Spitznagel, M.B., Strain, G., Devlin, M., Cohen, R., Paul, R., et al., 2012. Cognitive function in morbidly obese individuals with and without binge eating disorder. Compr. Psychiatry 53 (5), 490-495. https://doi.org/10.1016/j.comppsych. 2011.09.002.

Gioia, G.A., Isquith, P.K., 2004. Ecological assessment of executive function in traumatic brain injury. Dev. Neuropsychol. 25 (1-2), 135-158.

Goldberg, E., Podell, K., 2000. Adaptive decision making, ecological validity, and the frontal lobes. J. Clin. Exp. Neuropsychol. 22 (1), 56-68. https://doi.org/10.1076/ 1380-3395(200002)22:1;1-8;FT056.

Hagen, E., Erga, A.H., Hagen, K.P., Nesvag, S.M., McKay, J.R., Lundervold, A.J., Walderhaug, E., 2016. Assessment of executive function in patients with substance use disorder: a comparison of inventory- and performance-based assessment. J. Subst. Abuse Treat. 66, 1-8. https://doi.org/10.1016/j.jsat.2016.02.010.

Heatherton, T.F., Baumeister, R.F., 1991. Binge eating as escape from selfawareness Psychol. Bull. 110 (1), 86-108. https://doi.org/10.1037/0033-2909.110.1.86.

Heaton, R.K., Chelune, G.J., Talley, J.L., Kay, G., Curtiss, G., 1993. Wisconsin Card Sort Test. Psychologocal Assessment Resources, Odessa, FL.

Hudson, J.I., Hiripi, E., Pope, H.G., Kessler, R.C., 2007. The prevalence and correlates of eating disorders in the national comorbidity survey replication. Biol. Psychiatry 61 (3), 348-358. https://doi.org/10.1016/j.biopsych.2006.03.040.

Javaras, K.N., Pope, H.G., Lalonde, J.K., Roberts, J.L., Nillni, Y.I., Laird, N.M., et al., 2008.
. Co-occurrence of binge eating disorder with psychiatric and medical disorders. J. Clin. Psychiatry 69 (2), 266-273. https://doi.org/10.4088/JCP.v69n0213.

Keel, P.K., Brown, T.A., 2010. Update on course and outcome in eating disorders. Int. J. Eat. Disord. 43 (3), 195-204. https://doi.org/10.1002/eat.20810.

Keller, M.B., Lavori, P.W., Friedman, B., Nielsen, E., Endicott, J., McDonald-Scott, P., Andreasen, N.C., 1987. The longitudinal interval follow-up evaluation. A comprehensive method for assessing outcome in prospective longitudinal studies. Arch. Gen. Psychiatry 44 (6), 540-548.

Kelly, N.R., Bulik, C.M., Mazzeo, S.E., 2013. Executive functioning and behavioral impulsivity of young women who binge eat. Int. J. Eat. Disord. 46 (2), 127-139. https:// doi.org/10.1002/eat.22096.

Kittel, R., Brauhardt, A., Hilbert, A., 2015. Cognitive and emotional functioning in bingeeating disorder: a systematic review. Int. J. Eat. Disord. 48 (6), 535-554. https://doi. org/10.1002/eat.22419.

Kittel, R., Schmidt, R., Hilbert, A., 2017. Executive functions in adolescents with bingeeating disorder and obesity. Int. J. Eat. Disord. 50 (8), 933-941. https://doi.org/10. 1002/eat.22714.

Krämer, B., 1996. LIFE II Based Eating Disorders Interview, LIFE-II-BEI. Revised Version of the LIFE Eat II, Adapted for the German multicenter Study on Eating Disorders. Centre for Psychotherapy Research, Stuttgart, Germany.

Lavagnino, L., Arnone, D., Cao, B., Soares, J.C., Selvaraj, S., 2016. Inhibitory control in obesity and binge eating disorder: a systematic review and meta-analysis of neurocognitive and neuroimaging studies. Neurosci. Biobehav. Rev. 68, 714-726. https:// doi.org/10.1016/j.neubiorev.2016.06.041.

Leehr, E.J., Krohmer, K., Schag, K., Dresler, T., Zipfel, S., Giel, K.E., 2015. Emotion regulation model in binge eating disorder and obesity-a systematic review. Neurosci. Biobehav. Rev. 49, 125-134. https://doi.org/10.1016/j.neubiorev.2014.12.008.

Lena, S.M., Fiocco, A.J., Leyenaar, J.K., 2004. The role of cognitive deficits in the development of eating disorders. neuropsychology review. Neuropsychol. Rev. 14 (2), 99-113. https://doi.org/10.1023/B:NERV.0000028081.40907.de.

Lezak, M.D., Howieson, D.B., Loring, D.W., 2011. Executive functions and motor performance. In: Lezak, M.D., Howieson, D.B., Loring, D.W. (Eds.), Neuropsychological Assessment. Oxford University Press, New York, pp. 611-646.

Manasse, S.M., Forman, E.M., Ruocco, A.C., Butryn, M.L., Juarascio, A.S., Fitzpatrick, K.K., 2015. Do executive functioning deficits underpin binge eating disorder? A comparison of overweight women with and without binge eating pathology. Int. J. Eat. Disord 48 (6), 677-683. https://doi.org/10.1002/eat.22383.

Manasse, S.M., Juarascio, A.S., Forman, E.M., Berner, L.A., Butryn, M.L., Ruocco, A.C. 2014. Executive functioning in overweight individuals with and without loss-ofcontrol eating. Eur. Eat. Disord. Rev. 22 (5), 373-377. https://doi.org/10.1002/erv. 2304.

McAuley, T., Chen, S., Goos, L., Schachar, R., Crosbie, J., 2010. Is the behavior rating inventory of executive function more strongly associated with measures of impairment or executive function? J. Int. Neuropsychol. Soc. 16 (3), 495-505. https://doi. org/10.1017/S1355617710000093.

McClintock, S.M., Husain, M.M., Greer, T.L., Cullum, C.M., 2010. Association between depression severity and neurocognitive function in major depressive disorder: a review and synthesis. Neuropsychology 24 (1), 9-34. https://doi.org/10.1037/ a0017336.

Mobbs, O., Iglesias, K., Golay, A., Van der Linden, M., 2011. Cognitive deficits in obese persons with and without binge eating disorder. Investigation using a mental flexibility task. Appetite 57 (1), 263-271. https://doi.org/10.1016/j.appet.2011.04.023.

Mole, T.B., Irvine, M.A., Worbe, Y., Collins, P., Mitchell, S.P., Bolton, S., et al., 2015. Impulsivity in disorders of food and drug misuse. Psychol. Med. 45 (4), 771-782. https://doi.org/10.1017/S0033291714001834.

Mueller, S.T., 2009. PEBL: the psychology experiment building language [Computer experiment programming language].

Nelson, H.E., 1991. The Revised National Adult Reading Test Manual. NFER-Nelson, Windsor, UK.

Noens, I., Scholte, E., 2011. BRIEF-A: Executieve functies Gedragsvragenlijst Voor Volwassenen. Hogrefe Uitgevers B.V, Amsterdam.

Nolen-Hoeksema, S., Watkins, E.R., 2011. A heuristic for developing transdiagnostic models of psychopathology: explaining multifinality and divergent trajectories. Perspect. Psychol. Sci. 6 (6), 589-609. https://doi.org/10.1177/1745691611419672.

Osterrieth, P.A., 1944. Filetest de copie d'une figure complex: Contribution a l'etude de la perception et de la memoire [The test of copying a complex figure: a contribution to the study of perception and memory]. Archives de Psychologie 30, 286-356.

Rabin, L.A., Roth, R.M., Isquith, P.K., Wishart, H.A., Nutter-Upham, K.E., Pare, N., 2006. Self- and informant reports of executive function on the BRIEF-A in MCI and older adults with cognitive complaints. Arch. Clin. Neuropsychol. 21 (7), 721-732. https:// doi.org/10.1016/j.acn.2006.08.004.

Reitan, R., 1956. Trail Making test: Manual for Administration, Scoring, and Interpretation. Indiana University, Bloomington.

Roberts, M.E., Tchanturia, K., Treasure, J.L., 2010. Exploring the neurocognitive signature of poor set-shifting in anorexia and bulimia nervosa. J. Psych. Res. 44 (14), 964-970. https://doi.org/10.1016/j.jpsychires.2010.03.001.

Roberts, M.E., Tchanturia, K., Treasure, J.L., 2016. Overlapping neurocognitive inefficiencies in anorexia nervosa: a preliminary investigation of women with both poor set-shifting and weak central coherence. Eat. Weight. Disord. 21 (4), 725-729. https://doi.org/10.1007/s40519-016-0302-8.

Roth, R.M., Isquith, P.K., Gioia, G.A., 2004. Behavior Rating of Executive Functioning Adult Version. Psychological Assessment Resources, Lutz, FL USA.

Rouel, M., Raman, J., Hay, P., Smith, E., 2016. Validation of the Behaviour Rating Inventory of Executive Function - Adult Version (BRIEF-A) in the obese with and without binge eating disorder. Eat. Behav. 23, 58-65. https://doi.org/10.1016/j. eatbeh.2016.07.010. 
Sheehan, D.V., Lecrubier, Y., Sheehan, K.H., Amorim, P., Janavs, J., Weiller, E., et al., 1998. The Mini-International Neuropsychiatric Interview (M.I.N.I.): the development and validation of a structured diagnostic psychiatric interview for DSM-IV and ICD10. J. Clin. Psychiatry 59 (Suppl 20), 22-33.

Snyder, H.R., 2013. Major depressive disorder is associated with broad impairments on neuropsychological measures of executive function: a meta-analysis and review. Psychol. Bull. 139 (1), 81-132. https://doi.org/10.1037/a0028727.

Strauss, E., Sherman, E.M.S., Spreen, O., 2006. A Compendium of Neuropsychological Tests: Administration, Norms, and Commentary, Third ed. Oxford University Press, Oxford.

Stroop, J., 1935. Studies of interference in serial verbal reaction. J. Exp. Psych. 18, 643-662.

Svaldi, J., Brand, M., Tuschen-Caffier, B., 2010. Decision-making impairments in women with binge eating disorder. Appetite 54 (1), 84-92. https://doi.org/10.1016/j.appet. 2009.09.010.

Svaldi, J., Naumann, E., Trentowska, M., Schmitz, F., 2014. General and food-specific inhibitory deficits in binge eating disorder. Int. J. Eat. Disord. 47 (5), 534-542. https://doi.org/10.1002/eat.22260.

Tabachnick, B.G., Fidell, L.S., 2013. Using Multivariate Statistics, Sixth ed. Pearson Education, Boston, USA.

Van den Eynde, F., Guillaume, S., Broadbent, H., Stahl, D., Campbell, I.C., Schmidt, U., et al., 2011. Neurocognition in bulimic eating disorders: a systematic review. Acta Psychiatr. Scand. 124 (2), 120-140. https://doi.org/10.1111/j.1600-0447.2011. 01701.x.

Van der Does, A.J., 2002. Beck Depression Inventory - II (BDI-II-NL). Swets \& Zeitlinger,
Lisse.

Voon, V., 2015. Cognitive biases in binge eating disorder: the hijacking of decision making. CNS Spectr 20 (6), 566-573. https://doi.org/10.1017/ S1092852915000681.

Voon, V., Irvine, M.A., Derbyshire, K., Worbe, Y., Lange, I., Abbott, S., et al., 2014. Measuring "waiting" impulsivity in substance addictions and binge eating disorder in a novel analogue of rodent serial reaction time task. Biol. Psychiatry 75 (2), 148-155. https://doi.org/10.1016/j.biopsych.2013.05.013.

Wechsler, D., 2012. Wechsler Adult Intelligent Scale, Dutch Version, Fourth ed. Ipskamp drukkers b.v, Enschede.

Wu, M., Brockmeyer, T., Hartmann, M., Skunde, M., Herzog, W., Friederich, H.C., 2014. Set-shifting ability across the spectrum of eating disorders and in overweight and obesity: a systematic review and meta-analysis. Psychol. Med. 44 (16), 3365-3385. https://doi.org/10.1017/S0033291714000294.

Wu, M., Brockmeyer, T., Hartmann, M., Skunde, M., Herzog, W., Friederich, H.C., 2016. Reward-related decision making in eating and weight disorders: a systematic review and meta-analysis of the evidence from neuropsychological studies. Neurosci. Biobehav. Rev. 61, 177-196. https://doi.org/10.1016/j.neubiorev.2015.11.017.

Wu, M., Giel, K.E., Skunde, M., Schag, K., Rudofsky, G., de, Z.M., Friederich, H.C., 2013a. Inhibitory control and decision making under risk in bulimia nervosa and bingeeating disorder. Int. J. Eat. Disord. 46 (7), 721-728. https://doi.org/10.1002/eat. 22143.

Wu, M., Hartmann, M., Skunde, M., Herzog, W., Friederich, H.C., 2013b. Inhibitory control in bulimic-type eating disorders: a systematic review and meta-analysis. PLoS One 8 (12), e83412. https://doi.org/10.1371/journal.pone.0083412. 